\title{
Phenotypic Plasticity of Spineless Safflower (Carthamus tinctorius L.) Cultivars in Response to Exogenous Application of Salicylic Acid under Rainfed Climate Conditions
}

\section{Adnan Arshad ${ }^{1 *}$, Huma Qamar ${ }^{2}$, Ristina Siti-Sundari ${ }^{3}$, Zhang Yue ${ }^{1}$, Muhammad Zubair $^{2}$, Muhammad Ali Raza ${ }^{4}$, Muhammad Habib-ur-Rehman ${ }^{5}$ and Lizhen Zhang ${ }^{1 *}$}

${ }^{1}$ College of Resources and Environmental Sciences, China Agricultural University, Beijing 100193 China; ${ }^{2}$ Oilseeds Research Institute, Ayub Agriculture Research Institute, Faisalabad 38000, Pakistan; ${ }^{3}$ Agriculture Faculty, University of Perjuangan, Jl. PETA No. 177 Tasikmalaya 46115 Indonesia; ${ }^{4}$ College of Agronomy, Sichuan Agricultural University, Chengdu 611130, China; Institute of Crop Science and Resource Conservation (INRES) University Bonn, Germany.

Abstract | Unpredictable and unseasonal extreme climate, prolonged droughts, rise in temperatures, and erratic rainfall are common factors affecting crop productions in rainfed areas worldwide. This research intended to identify spineless Safflower (Carthamus tinctorius L.) performance in acclimating changing climate, as safflower has gained prominence as an oilseed industry due to its hardiness in nature. A two-factor factorial experiment using completely randomized block design (RCBD) followed by five spineless safflower cultivars and five concentrations of salicylic acid (SA) in three replications was conducted. The safflower promising genotypes viz; C1 (L16358), C2 (L16378), C3 (L26748), C4 (L26754), and C5 (L16385) were tested against SA1: $0 \mathrm{mM}$, SA2: $0.25 \mathrm{mM}$, SA3: $0.50 \mathrm{mM}$, SA4: $0.75 \mathrm{mM}$, and SA5: $1.00 \mathrm{mM}$ salicylic acid concentrations. The result indicated that most responsive cultivar to rainfed conditions was C3 (L26748) under SA4 $(0.75 \mathrm{mM})$ level, showing an increase in head diameter, seed weight, harvest index, oil yield stem, while 7.3-days to flowering maturity were reduced after C5, and C4 (26754). SA3-C5 promoted 8.01 days earlier maturity, maximum seed plant ${ }^{-1}$, while SA3-C3 resulted in a significant increase in yield and oil content. SA3 and SA4 showed substantial plasticity to maximum phenology parameters of C3, C4, and C5. Safflower treated with salicylic acid could adapt to wide range even though in the extreme weather and drought conditions in rainfed agriculture. Spineless safflower cultivars could be a future way forward as a potential parallel crop to ensure a sustainable source of production in rainfed regions worldwide.

Received | March 27, 2020; Accepted | July 20, 2020; Published | October 05, 2020

*Correspondence | Adnan Arshad and Lizhen Zhang, College of Resources and Environmental Sciences, China Agricultural University, Beijing 100193 China; Email: ad@cau.edu.cn, zhanglizhen@cau.edu.cn

Citation | Arshad, A., H. Qamar, R. Siti-Sundari, Z. Yue, M. Zubair, M.A. Raza, M.H. Rehman and L. Zhang. 2020. Phenotypic plasticity of spineless safflower (Carthamus tinctorius L.) cultivars in response to exogenous application of salicylic acid under rainfed climate conditions. Pakistan Journal of Agricultural Research, 33(4): 729-743.

DOI | http://dx.doi.org/10.17582/journal.pjar/2020/33.4.729.743

Keywords | Plasticity evaluation, Climate-smart management, Rainfed conditions, Salicylic acid, Spineless safflower

\section{Introduction}

$\mathrm{T}$ he global climate risk index (GCI) has ranked Pakistan among the six of ten most climate susceptible countries worldwide for three consecutive years by climate-related catastrophes (Edenhofer et al., 2014). Farming communities rely on their environments for every basic need of life including food security, the impact of climate change, and the onset of extreme weather events are (EWE) devastating. Rain-fed agriculture in Pakistan is highly vulnerable to extreme climate and weather that lead 
to crop failure and lower yields obtained due to uneven topography, low soil fertility, erratic rainfall, higher temperature above normal, prolong droughts (Ahmad et al., 2015; IPCC, 2018).

Climate change is creating an alarming situation for sustainable agriculture and food security specially in rain-fed regions. Due to those, the extreme weather conditions as well as shifting patterns of precipitation results in the crop yield reduction (Cisse et al., 2019; Raza et al., 2019). Length of growing period of a crop is affected by increasing temperature and uncertain precipitation which eventually leads to crop failure and decrease yield. Future climate projections depict that temperature expected to rise by $2.5^{\circ} \mathrm{C}$ up to 2050 (Ahmad et al., 2017). The evidence of the fashion of global rainfall is not clear because of significant regional gaps in spatial coverage and temporary deficiencies in the data. These shifts in climate caused the drought, is most challenging in several countries in the world, including Pakistan (Nasim et al., 2018).

Worldwide air temperature is expected to increase $1.5-2^{\circ} \mathrm{C}$ for RCP 6.0 , and RCP 8.5 and will continue increasing beyond twenty-first century under each RCP scenario. Under RCP 2.6, RCP 4.5, RCP 6.0 and RCP 8.5 scenario, projected increase in global mean temperature is likely to increase by $0.3-1.0^{\circ} \mathrm{C}$, $1.1-2.6^{\circ} \mathrm{C}, 1.4-3.1^{\circ} \mathrm{C}$ and $2.6-4.8^{\circ} \mathrm{C}$, respectively. (Amin et al., 2018a; Rahman et al., 2018; Arshad et al., 2019). It means that temperature will increase drastically in arid areas of the subcontinent and western part of China. The impact of climate change on cereal crop production, particularly wheat, showed yield reduction in China (-17.5), Australia (-32\%), and Pakistan (-50\%) (Tao and Zhang, 2013). Punjab province in Pakistan has observed 35,000 acres (150,000 tons) of wheat damages. During Rabi season (2018-19), wheat has been cultivated over 6.54 Mha in Punjab and the target set for production at 19.5 million tons (GOPASP 2016/17, 2018). However, now a mature crop of wheat may reduce by 50,000 tons due to the impact of adverse weather conditions, but Pakistan remains one of the world's largest vegetable oil importers. It has been reported that Southern and Central Punjab expected to face severe weather events.

Modelling climate change assessment depicted that erratic rainfall with higher intensity would increase across the region, but intense rainfall would likely to occur during the monsoon season (Amin et al., 2018b; Nasim et al.,2018; Rahman et al., 2018). Sustainability of the crop production under changing pattern of climate is a critical challenge for countries susceptible to extreme weather events. Therefore, adaptation measures are required to reduce climate vulnerabilities. The detrimental impact of climate change can be moderated by the introduction of parallel crop cultivars highly tolerant of unexpected environmental changes, along with some modifications in current production technologies (IPCC, 2014).

The total edible oil consumption in Pakistan is about 4 Mln MT but the local production only contributed up to $0.4 \mathrm{Mln} \mathrm{MT}$, rest of 3 Mln MT imported from other countries (OECD/FAO, 2016). Maximum reliance on imports leading exchange rate risk factors in sustainable agriculture production in the country. The imports of oilseeds during 2019/20 are expected at a record 3.8 million tons, up to $7 \%$ from the preceding year 2018-2019 (Lovelli et al., 2007). The primary local seed oil production sources are the cottonseed, mustard/rapeseed, and sunflower, but Pakistan remains one of the world's largest edible oil importer.

Safflower (Carthamus tinctorius L) can be a virtuous candidate crop in a rain-fed agro-ecosystem worldwide, particularly spineless cultivars. Because of its spineless potential, easy crop management, growth even under drought condition as well as the economic value in terms of both oil and seed, (Canvin, 1965; Aydın and Sarptaş, 2018) indicated that safflower could be helpful in reducing import of edible oil each year even in this changing climatic conditions. Safflower seed contains 35 to $45 \%$ highquality vegetable oil. Oil is considered to be good for health and cooking oil but prolong drought condition can decrease its oil productivity from to $10-14 \%$, respectively. Local produce of edible oil is not enough to fulfill the requirement. Pakistan is the third-largest importer of edible oil all over the world (USDA, 2016; GOPASP 2016/17, 2018). During 2016-17 844,990 tons of edible oil was produced in the country to fulfill local requirements, it only meets $28-32 \%$ of domestic demand, and the rest of requirement was accomplished by $11 \%$ from imported edible oil and $61 \%$ through direct imports according to data of Pakistan Bureau of Statistics (PBS). Safflower plant parts have different uses, i.e., the flower used in dye making, paints, soaps, oil in different medicines and 
baking recipes, stem and leaves for fodder forage, and hey as animal feed (Lovelli et al., 2007). Seed oil of safflower is an excellent source of thiamine, pyridoxine, folate, and $100 \mathrm{~g}$ of seeds contain; a) $90-100 \%$ of the $\mathrm{RDI}$ of vitamin $\mathrm{B} 1 \mathrm{~b}) 90 \%$ of the RDI of vitamin B6; c) $40 \%$ of the RDI of vitamin B9. It is also a rich source of iron, magnesium, and phosphorus (Canvin, 1965; Lovelli et al., 2007; Aydın and Sarptaş, 2018).

Among all oilseed crops, safflower has desired traits such as resilience to biotic and abiotic stresses as well as suitable for good quality oil with valuable unsaturated fatty acids (Canvin, 1965). Safflower is mostly grown in dry as well as rain-fed zones of the world. The crop germination is followed by slowgrowing rosette stage during which numerous leaves are produced near ground level, at rosette stage young safflower plants are resistant to cold and frost (Zhou et al., 2014). Safflower plants has an extensive taproot system that can break up hardpans of soil and create channels in the soil profile which facilitate air and water movement in soil layers, while it can be used as a tool for managing salinity and waterlogging conditions as well. Safflower is more drought accepting than other oilseed crops (Aydın and Sarptaş, 2018; Hussain and Al-Dakheel, 2018). Crop sown in spring, moisture deficit at growth stages specially during flowering and seed filling stages, caused a decrease in yield and other yield related attributes.

Salicylic acid is one of the phenols phytohormones involved in different plant growth and development phases, i.e., photosynthetic rate and assimilation of $\mathrm{CO}_{2}$ (Espanany et al., 2016; Hussain et al., 2016). Stomata closure, transportation, and ion uptake. Several studies carried out under laboratory and field conditions strongly suggested that salicylic acid plays an essential role in many biological responses in plants (Cai et al., 2015), especially the defense mechanism against biotic and abiotic stresses, which are responsible for poor plant growth and yield quality. Salicylic acid is held responsible for the endogenous signal used to maintain membrane integrity and mediating the hypersensitive systematic resistance against pathogen and disease attacks (Afzal et al., 1560; Baghizadeh, 2011; Gupta et al., 2013). It has shown many benefits for human health as it is useful in the prevention of cardiovascular diseases.

Exogenous application of nutrients and plant growth regulators resulted in better and improved flowering and quality parameters (Kabiri et al., 2014; Hussain et al., 2016). It is the quickest and very economical way to provide nutrients directly to the plant tissues and organs without any field losses. These smart techniques in the agriculture cropping system help to cope with biotic stresses and climatic damages (Espanany et al., 2016; Imran et al., 2018).

The existing research test several SA levels and biological approaches for phenology and yield calculation to estimate the best climate-adaptive spineless safflower cultivars. The research question of this study was set as: a) What concentrations of salicylic acid (SA) perform efficiently to tackle environmental stresses and produce high seed and oil yield of safflower, if so, to what extent? b) Evaluate the best performing and climate adaptive crop cultivar show maximum resistance and produce highest yield.

\section{Materials and Methods}

\section{Site selection}

Field experiments were conducted during the 20152016 growing seasons at the agronomy project research site near UET-Taxila, Punjab, Pakistan. The latitude $33^{\circ} 42^{\prime} \mathrm{N}$ longitude of $72^{\circ} 52^{\prime} \mathrm{E}$ and the altitude $512 \mathrm{~m}$ from the sea level. The annual rainfall of this area is $590-650 \mathrm{~mm}$ (PMD, 2016) with annual average temperature $21.6^{\circ} \mathrm{C}$, but the recent time the temperature had increased up to $<30^{\circ} \mathrm{C}$ and average relative humidity declined (38-56\%) during the growing season of safflower. The soil at the experimental site belonged to the major group of Indo-Gangetic alluvium (sand, silt, and clay was $30.68,40.42$ and $29.13 \%$, respectively), having 1.36 $\left(\mathrm{DSM}^{-1}\right)$ electrical conductivity (EC) besides $7.9 \mathrm{pH}$, $0.76 \%$ organic carbon, $163 \mathrm{~kg} \mathrm{ha}^{-1}$ available nitrogen, $16.8 \mathrm{~kg} \mathrm{ha}^{-1}$ available phosphorus and $372 \mathrm{~kg} \mathrm{ha}^{-1}$ available potassium.

\section{Field preparation and sowing}

The field was prepared, pulverized seedbed, plowing followed by planking before planting. The experiment led out in a randomized complete block design (RCBD) using a factorial arrangement with three treatments and three replications. Safflower was planted using plots drill (Model 3P600, Plains Drill) using a seed rate of $30 \mathrm{~kg} \mathrm{ha}^{-1}$. Plants has branching capacity, and the best plant population ranges between 1.0-1.1 lakh/ha. Emergence rate was recorded 80 to $85 \%$ emergence rate target population of 625,000 
plants/ha was maintained. The plot size was $8 \mathrm{~m} \times 4$ $\mathrm{m}$, with a distance of $40 \mathrm{~cm}$ between rows. For sowing seed was obtained from Department of Agronomy PMAS-Arid Agriculture University. Fertilizer was applied at the time of planting@ $89 \mathrm{~kg} \mathrm{~N} \mathrm{ha}^{-1}$ and 19 $\mathrm{kg} \mathrm{P} \mathrm{ha}{ }^{-1}$ through urea and di-ammonium phosphate. Additional fertilizer was applied in the form of monoammonium phosphate at a rate Harvesting was done at senescence using a John Deere Model 4420 mix with a straw chopper combine harvester.

\section{Data recorded}

Field experiment measurements were recorded by using techniques (Cleland and Tanaka, 1979) at various growth as well as developmental stages. Agronomic traits along with yield contributing traits such as leaf area index, stem diameter $(\mathrm{cm})$, head diameter $(\mathrm{cm})$, number of primary branches plant ${ }^{-1}$, number of secondary branches plant ${ }^{-1}$, days taken to flowering, days takes to flowering maturity, capitulum filling duration, crop maturity, number of achene/seed head $^{-1}$, weight of 1000 seeds $(\mathrm{g})$, actual yield $\left(\mathrm{kg} \mathrm{ha}^{-1}\right)$, Oil recovery (\%), economic yield $\left(\mathrm{kg} \mathrm{ha}^{-1}\right)$, Harvest index (\%) and oil quality were recorded.

\section{Coding and statistical analysis}

Safflower cultivar seed comprised of C1 (L16358), C2 (L16378), C3 (L26748), C4 (L26754), and C5 (L16385). Salicylic acid concentrations tested were SA1: control, SA2: $0.25 \mathrm{mM}$, SA3: $0.50 \mathrm{mM}$, SA3: $0.75 \mathrm{~mm}$ and SA5: $1.00 \mathrm{~mm}$ [34]. A foliar spray of different concentrations of SA was used three times (at 1-week intervals) by T-Jet sprayer at the stem elongation stage. The data were analyzed by ANOVA and $t$-test, followed by DMRT post hoc test $(\mathrm{P}<0.05$; IBM, SPSS Statistics). The results visualization was supported by $\mathrm{R}$ version (3.6.1) and SigmaPlot.

\section{Results and Discussion}

The growing season of 2015-2016 was stressful for rain-fed agricultural crop production in the area. The months of April and May were warmer in 2016 compared with the year 2015. During the growing season, rainfall received ranged from 100-105 mm in 2015 to $115-120 \mathrm{~mm}$ in 2016 . The data about the growth and yield parameters of five spineless safflower cultivars as influenced by salicylic acid are analyzed and discussed in Table 1.

Analysis of variance indicated a significant difference among cultivar for the number of leaf and leaf area. But, plant height, a number of primary and secondary branches expressed highly significant difference. A highly significant effect was shown in response to salicylic acid treatment on leaf area, the number of primary and secondary branches, and a significant effect on plant height and non-significant effect on the number of leaves. However, all of the treatments gave significant interface and highly significant interaction on branch growth, either primary or secondary. So, the test followed multiple comparisons by the DMRT test to know which treatment gave. Partially, C4 and C5 showed (Table 2) the best plant height, and the interaction was observed in the case of SA5-C4 $(172.90 \mathrm{~cm})$ and SA2-C2 $(172.38 \mathrm{~cm})$ respectively.

The foliar spray of salicylic acid and safflower cultivars had shown significant interactions with the number of leaves per plant. Salicylic acid at $0.25 \mathrm{mM}$ has an increased number of leaves of $\mathrm{C} 1$, and $\mathrm{C} 2$ cultivars, $0.75 \mathrm{mM}$ level of SA also enhanced in $\mathrm{C} 1$, respectively. The maximum leaves were recorded e in interaction SA4-C1 (29.02), followed by SA2-C1 (26.89) and SA2-C2 (26.19), respectively.

SA concentration of 0.25 and $0.5 \mathrm{mM}$ appreciably increased the leaf area of $\mathrm{C} 1, \mathrm{C} 2$, and $\mathrm{C} 2, \mathrm{C} 3$. The maximum size of the leaf area was recorded under SA3-C2 $\left(151.63 \mathrm{~cm}^{2}\right)$, and then SA3-C3 (149.04 $\mathrm{cm}^{2}$ ). The highest numbers of primary branches per plant (16.56) were produced in response to SA5-C3. Safflower cultivar C4 in any salicylic acid concentration had characterized higher average genetic growth, and C5 had no significant interaction under low SA levels. The result showed that the highest concentrations of SA produced a higher number of primary branches on a plant in case of SA4-C5 (13.93). However, C3 and C5 produced the maximum number of secondary branches where 0.25 $\mathrm{mM}$ SA was applied, and the further reduction was observed in the number of branches at $0.75-1 \mathrm{mM}$ SA levels. The highest numbers of secondary branches per plant (45.58) were achieved by $\mathrm{C} 2$, where $0.5 \mathrm{~mm}$ salicylic acid was sprayed. Cultivars $\mathrm{C} 4, \mathrm{C} 3$, and $\mathrm{C} 5$ produced maximum head diameter in sequence 3.04 $\mathrm{cm}, 2.72 \mathrm{~cm}$, and $2.71 \mathrm{~cm}$ in foliar spray $0.5 \mathrm{mM} \mathrm{SA}$. Other cultivar produced the same head diameter but lower than the upper cultivars in response to SA4-C2 produced a maximum number (35.5) of heads per plant. 
Table 1: Analysis of variance of growth parameters after foliar application of salicylic acid (SA) levels on spineless safflower cultivars under rain-fed conditions during 2015 to 2016 growing season.

\begin{tabular}{|c|c|c|c|c|c|c|c|c|c|}
\hline Source & (PH) & (NL) & (LA) & (NPB) & (NSB) & (HD) & (ST) & (DFI) & (DFM) \\
\hline Corrected Model^ ${ }^{\wedge}$ & 3.316 & 2.486 & 3.912 & 8.315 & 12.50 & 4.95 & 5.79 & 29.439 & 8.53 \\
\hline Intercept ${ }^{\wedge \wedge}$ & $13,186.45$ & $1,180.20$ & $2,367.12$ & $2,940.43$ & $1,690.44$ & 7877.12 & 3488.51 & $1,607,054.32$ & $41,177.08$ \\
\hline Block & .27 & 3.35 & 1.15 & .227 & 0.59 & .70 & 2.25 & .11 & .00 \\
\hline SA & $2.03^{*}$ & 1.30 & $8.45^{* *}$ & $11.00^{* *}$ & $8.46^{* *}$ & $16.09^{* *}$ & $8.649^{* *}$ & $61.73^{* *}$ & $30.05^{* *}$ \\
\hline $\mathrm{V}$ & $13.32^{* *}$ & $5.88^{*}$ & $5.02^{*}$ & $28.61^{* *}$ & $49.94^{* *}$ & $8.78^{* *}$ & $25.361^{* *}$ & $62.25^{* *}$ & $12.52^{* *}$ \\
\hline Interaction of $\mathrm{SA}^{*} \mathrm{~V}$ & $1.52^{*}$ & $1.83^{*}$ & $2.85^{*}$ & $3.58^{* *}$ & $5.63^{* *}$ & 1.74 & .62 & $16.83^{* *}$ & $3.22^{* *}$ \\
\hline
\end{tabular}

^: Corrected model is the influence of the independent variable simultaneously on the dependent variable, where values are nonsignificant or significant, respectively. ^^: Variation/change values of the dependent variable without the existence of independent variable, so; the higher values of intercept are certainty because of variable factors that are not included in the analysis and mightily change along with growth without traits (cultivars and SA levels). PH: Plant Height; NL: Number of the Leaf; LA: Leaf Area; NPB: Number of Primary Branch; NSB: Number of Secondary Branch; HD: Head Diameter; ST: Stem Thickness; DFI: Days to Flowering Initiative; DFM: Days to Flowering Maturity.

Table 2: Analysis of variance of yield parameters after foliar application of salicylic acid (SA) levels on spineless saflower cultivars under rain-fed conditions during 2015 to 2016 growing season.

\begin{tabular}{|c|c|c|c|c|c|c|c|c|c|}
\hline Source & (DCM) & (NSP) & (TSW) & $(\mathrm{FW})$ & (CFD) & (DW) & (HI) & (SOC) & (OY) \\
\hline Corrected Model^ & 14.44 & 15.83 & 6.56 & 9.191 & 11.259 & 11.17 & 4.89 & 6.91 & 15.08 \\
\hline Intercept $\mathrm{t}^{\wedge \wedge}$ & 755762.17 & $8,318.70$ & $12,773.63$ & $14,987.079$ & $216,188.31$ & $42,664.72$ & $0,884.10$ & $581,423.34$ & $45,354.27$ \\
\hline Block & .37 & 1.84 & .11 & 3.229 & 5.915 & 0.21 & 1.00 & 1.80 & 0.53 \\
\hline SA & $32.00^{*}$ & $21.18^{* *}$ & $18.04^{* *}$ & $23.347^{* *}$ & $15.852^{* *}$ & $12.62^{*}$ & $24.78^{*}$ & $31.41^{* *}$ & $26.34^{* *}$ \\
\hline V & $59.38^{*}$ & $37.46^{* *}$ & $14.16^{* *}$ & $28.904^{* *}$ & $30.012^{* *}$ & $51.38^{* *}$ & $6.08^{*}$ & $6.93^{* *}$ & $62.32 * *$ \\
\hline Interaction_SA*V & .57 & $10.84^{* *}$ & $2.60^{*}$ & $1.470^{*}$ & $6.090^{* *}$ & $2.13^{*}$ & .11 & 1.41 & $2.27^{*}$ \\
\hline
\end{tabular}

*: Corrected model is the influence of the independent variable simultaneously on the dependent variable, where values are non-significant or significant, respectively. ${ }^{*}$ : Variation/change values of the dependent variable without the existence of independent variable. so; the higher values of intercept are certainty because of variable factors that are not included in the analysis and mightily change along with growth without traits (cultivars and SA levels). DCM: Days Crops Maturity; NSP: Number of Seed per plant; TSW: Total of 1000 Seed Weight; FW: Fresh Weight; CFD: Capitulum Filling Days; DW: Dry Weight; HI: Harvest Index \%; SOC: Seed Oil Content; OY: Oil Yield.

Amongtheyield formingtraits, thenumberofheads and seeds per head were significantlyinfluenced, and results (Tables 1 and 2) indicated a highly significant effect on all parameters against both the treatments. The interaction was found significant for the days to initiate flowering and capitulum filing duration but non-significant for head diameter and stem thickness. When one of the treatments indicated, significant effect, DMRT was applied for multiple comparisons. Maximum days taken to Capitulum filling were observed for C2 (25.97 days) in control plots. The highest level of SA $(1 \mathrm{mM})$ enhanced capitulum filling resulting in earlier maturity (22.47 days) in C5 plots, followed by $\mathrm{C} 1$.

Maximum days (125.37) to flowering initiation were observed in control, and all the cultivars initiated to flowering subsequently very late. The earliest days to flowering initiation was observed where $0.75 \mathrm{mM}$ (SA4) salicylic acid was applied with 115.43 days for $\mathrm{C} 2$ and 115.60 days for C1. Early flowering maturity was observed (8.01 and 8.66 days; Table 2) in the case of C5 and C3 when $0.50 \mathrm{mM}$ SA foliar spray was tested. The plot of $\mathrm{C} 2$ completed flower maturation in 8.84 days when $0.75 \mathrm{mM}$ SA was sprayed under field conditions. The other treatment, either safflower cultivars or SA levels, were recorded more than nine days for maturity.

Spineless safflower phenological phases completion performance was influenced by both cultivars and salicylic acid treatments either each treatment or interaction between those mentioned variables such as days required for flowering maturation, seeds on a plant, thousand seed weight as well as biological yield parameters, except there was no significant interaction for days required for maturity. Data analysis pertaining to the number of days required for flowering completion or maturity presented in Table 2 revealed that there was no substantial difference in days required for flower maturity at the control and highest level $(1 \mathrm{~mm})$ of SA. Less days were taken to 
flowering maturity by $\mathrm{C} 5$ and $\mathrm{C} 3$ in response to 0.5 $\mathrm{mm}$, and $\mathrm{C} 2$ against $0.75 \mathrm{mM} \mathrm{SA}$ concentration in sequence reached 8.01 days, 8.66 days, and 8.84 days in plots mentioned above. Each treatment significantly influenced days required for crop maturity. Days required for the maturity of cultivars were fastened by SA level $0.75 \mathrm{mM}$ application, which lead C4 to take 199.37 days, followed by C3 201.60 days to crop maturity. The interaction SA4-C4, (0.75mM) counted for significantly fewer days taken to maturity among all plots. Maximum days (215.90) to maturity were seen in the plot receiving SA1-C1.

Seed yields were significantly influenced by the various levels of SA management practices in this study (Table 2). The interaction among cultivar $\mathrm{C} 1$ and 0.75 $\mathrm{mM}$ SA concentration maximized the number of seeds on a plant (50.77). The second interaction was observed between the SA2-C4 treated plots, where 46.7 seeds per plant were produced. By increasing concentration SA from 0.5 to $1 \mathrm{mM}$. The number of seeds per plant of $\mathrm{C} 1$ increased. SA application exhibited a decreasing effect for C2in sequence from high to low such as SA2-C2 (42.51), SA4-C2 (40.59), and SA5-C2 (38.98). The response of C4 to concentrations of SA from higher to lower was as: C4SA2 (46.74), C4SA3 (40.86), C4SA5 (40.42), and C4SA4 (36.55). Thousands of seed weight of all the cultivars were statistically different under the influence of SA maximum levels. The maximum result of 1000 seed weight was recorded in SA5-C2 $(47.94 \mathrm{~g})$. SA levels enhanced 1000s seed weight and were extended consistently up to $1 \mathrm{mM} \mathrm{SA}$, followed by $0.75-$ and $0.5-\mathrm{mM}$ rates, respectively.

Biological yield is an essential matter for safflower production and productivity, mainly when grown for energy purposes. SA application showed a significant effect on biological yield, and SA3-C4 resulted in a higher biological yield of 3,105.67 $\mathrm{kg} \mathrm{ha}^{-1}$ over SA3-C3 $\left(2,824.67 \mathrm{~kg} \mathrm{ha}^{-1}\right)$. SA4-C4 produced the highest biological yield $\left(3,436.33 \mathrm{~kg} \mathrm{ha} \mathrm{ha}^{-1}\right)$. The safflower showed different yield parameters, particularly economical yield, harvest-index, oil content (\%), and oil recovery in each factor. There was significant interaction was also observed for various parameters except for harvest index and oil content (Table 1) Yield components analysis showed C3 obtained the higher dry weight of $435.67 \mathrm{~kg} \mathrm{ha}{ }^{-1}$ and $422.24 \mathrm{~kg} \mathrm{ha}^{-1}$ when it was treated by SA3 and SA4, respectively. The foliar application of SA on safflower cultivars encouraged higher dry weight, especially the highest performance obtained by $\mathrm{C} 3$ cultivar of spineless safflower.

The current study, the statistical analysis revealed significant differences partially due to concentrations of salicylic acid and safflower cultivar regarding oil content (Table 3). The interactive effects of salicylic acid applications and safflower cultivars were significant regarding oil percentage either vertically or horizontally. Maximum oil content (33.84 \%) was achieved by SA4-C 5 interaction followed by SA4-C4 $(32.95 \%)$ when the same level of SA was sprayed. The lower seed oil contents were observed in plots SA1-C1 and SA1-C2 while the rest of the treatments differed at varying degrees for oil percentage among all the Safflower Cultivars.

The existing study evaluated the effect of different levels of SA on oil yield produced by plants under rain-fed climatic conditions (Table 3 ). The maximum oil yield was resulted by SA3-C3 $\left(144.30 \mathrm{~kg} \mathrm{ha}^{-1}\right)$ and SA4-C3 (140.07 $\left.\mathrm{kg} \mathrm{ha}^{-1}\right)$ and further declined (134.27 $\left.\mathrm{kg} \mathrm{ha}{ }^{-1}\right)$ were reported followed by the $1 \mathrm{~mm}$ SA level. The safflower cultivars and SA levels were partially significant for the harvest index of safflower. The maximum harvest index was on SA4-C3 (17.91\%) treatment, followed by equated with a lower index of $12.95 \%$ in SA1-C5.

The present study evaluated the effect of different levels of SA on spineless safflower cultivars to identify the climate adaptation to harvests maximum yield. It has been shown that salicylic acid acts as an endogenous signal molecule accountable for inducing stress tolerance in plants. In our experiment, the exogenous application of salicylic acid has influenced growth and yield parameters of spineless safflower cultivars as stated by (Gupta et al., 2013; Wani et al., 2017) that salicylic acid promoted shoot and root growth in different crops). The interface between genotypes and time (year) for sowing safflower seed affected some agronomic characters, particularly plant height (153.7 $\mathrm{cm}), 48.2 \mathrm{gr}$ for 1000 seed weight, $270.5 \mathrm{~kg} / \mathrm{ha}$ for yield, 37.9 for oil content in winter for L597684 at Turkey (Cai et al., 2015).

The pattern of variation in height among different cultivars understudy might be due to the genetic characterization or higher temperature, and interaction of both cultivar and salicylic acid concentration. The number of leaves determines plant photosynthetic capacity, which usually affects the final productivity 
Table 3: Interaction of growth and yield parameters of saflower spineless cultivars after foliar application of salicylic acid (SA) treatments under rainfed conditions during 2015 to 2016 growing season to evaluate adaptation performance.

\section{Treat- PH NL LAI NPB NSB HD ST DFI DFM CFD DTM NS $\begin{array}{lllll}\text { ment } & (\mathbf{c m}) & \left(\mathbf{c m}^{2}\right) & (\mathbf{c m}) & (\mathbf{c m})\end{array}$}

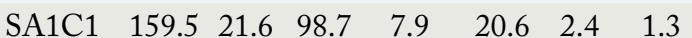
bc-bc a-b a-abc a-a bc-a a-b a-b

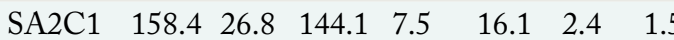
abc-a a-b b-b a-ab b-a a-a ab-a b-a

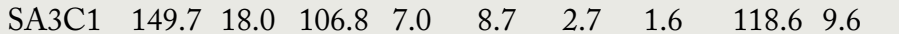
ab-a a-a ab-ab a-a a-a a-a b-ab b-b ab-b

$\begin{array}{llllllllll}\text { SA4C1 } & 144.7 & 29.0 & 125.1 & 11.2 & 26.8 & 2.6 & 1.6 & 115.6 & 10.0\end{array}$ a-a $\quad a-b \quad a b-a b \quad b-a \quad c-a \quad a-a \quad b-a \quad a-a \quad b c-b$

$\begin{array}{llllllllll}\text { SA5C1 } & 166.7 & 18.2 & 102.5 & 7.8 & 8.0 & 2.7 & 1.5 & 120.7 & 10.9\end{array}$ c-a $\quad a-a \quad a b-b \quad a-a \quad a-a \quad a-a \quad a b-a \quad c-b \quad d-b$

$\begin{array}{llllllllll}\mathrm{SA} 1 \mathrm{C} 2 & 145.2 & 21.5 & 120.3 & 5.4 & 13.3 & 2.2 & 1.3 & 121.7 & 11.0\end{array}$ $a b-a b \quad a-b \quad a b-c \quad a-a \quad a-a \quad a-b \quad a-b$

$\begin{array}{llllllll}\mathrm{SA} 2 \mathrm{C} 2 & 172.4 & 26.2 & 149.0 & 5.6 & 11.8 & 2.0 & 1.4\end{array}$ c-a a-b bc-b a-a a-a a-a a-a c-a ab-a

$\begin{array}{llllllllll}\text { SA3C2 } & 170.7 & 25.7 & 151.6 & 7.1 & 18.9 & 2.2 & 1.6 & 116.9 & 8.6\end{array}$ bc-b a-a c-c ab-a ab-b a-a ab-ab b-a a-a

$\begin{array}{llllllllll}\mathrm{SA} 4 \mathrm{C} 2 & 141.7 & 25.8 & 124.9 & 10.8 & 31.8 & 2.4 & 1.8 & 115.4 & 10.0\end{array}$ a-a a-ab abc-a c-a c-ab a-a b-b a-a bc-b

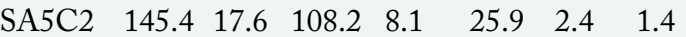
ab-ab a-a a-b b-a bc-b a-ab a-a

$\begin{array}{llllllll}\mathrm{SA} 1 \mathrm{C} 3 & 134.1 & 21.6 & 61.7 & 13.5 & 43.5 & 1.8 & 1.8\end{array}$ a-a a-b a-a ab-b a-b a-a a-c $a-a \quad a-a b \quad b-b$ a-c a-c ab-a ab-b a-a ab-a

$\begin{array}{llllllllll}\text { SA3C3 } & 145.4 & 16.1 & 149.0 & 11.8 & 37.5 & 2.6 & 1.9 & 121.1 & 8.7\end{array}$ a-a $a-a \quad b-c \quad a-b \quad a-c \quad a b-a \quad a b-b \quad a-c \quad a-a$

$\begin{array}{llllllllll}\mathrm{SA} 4 \mathrm{C} 3 & 139.4 & 17.5 & 122.7 & 11.0 & 34.9 & 2.7 & 2.1 & 122.8 & 8.8\end{array}$ a-a $\quad a-a \quad b-a \quad a-a \quad a-a b \quad c-a b \quad b-b \quad b-c \quad a-a$

$\begin{array}{llllllllll}\mathrm{SA} 5 \mathrm{C} 3 & 142.3 & 17.6 & 136.2 & 16.6 & 45.6 & 2.2 & 1.9 & 118.0 & 9.3\end{array}$ a-a a-a b-c b-b b-c ab-ab ab-b a-a ab-a

$\begin{array}{llllllllll}\text { SA1C4 } & 171.5 & 12.6 & 106.6 & 7.6 & 16.4 & 2.2 & 1.7 & 125.4 & 10.1\end{array}$ a-c a-a bc-bc a-a a-a a-b a-c d-c a-ab

$\begin{array}{llllllllll}\mathrm{SA} 2 \mathrm{C} 4 & 174.3 & 12.7 & 120.1 & 9.5 & 26.9 & 2.4 & 1.8 & 119.5 & 9.8\end{array}$ a-a a-a c-ab a-bc b-b a-a a-b a-a a-a

$\begin{array}{llllllllll}\mathrm{SA3C} 4 & 163.6 & 15.9 & 87.2 & 10.2 & 33.2 & 2.6 & 2.1 & 122.2 & 9.4\end{array}$ $a-a b$ ab-a ab-a a-b b-a a-a ab-b b-c a-b

$\begin{array}{llllllllll}\text { SA4C4 } & 170.8 & 17.5 & 107.2 & 10.3 & 26.6 & 3.0 & 2.3 & 123.1 & 9.7\end{array}$ a-b ab-a bc-a a-a b-a b-b b-b bc-c a-b

$\begin{array}{llllllll}\text { SA5C4 } & 172.9 & 23.6 & 76.9 & 10.0 & 31.2 & 2.6 & 1.8\end{array}$ a-c b-a a-a a-a b-a a-ab a-b

$\begin{array}{llllllll}\text { SA1C5 } & 173.4 & 20.7 & 71.9 & 7.5 & 20.2 & 1.7 & 0.9\end{array}$ $a-c \quad a-b \quad a-a b \quad a-a \quad a-a \quad a-a \quad a-a$

$\begin{array}{llllllll}\mathrm{SA} 2 \mathrm{C} 5 & 172.2 & 15.1 & 103.8 & 8.3 & 25.4 & 2.2 & 1.2\end{array}$ a-a $\quad a-a \quad a-a \quad a-a b \quad a-b \quad b-a \quad a-a$

$\begin{array}{llllllll}\text { SA3C5 } & 160.5 & 16.1 & 131.3 & 9.7 & 32.5 & 2.4 & 1.6\end{array}$ $a-a b \quad a-a \quad a-b c \quad a b-b \quad a-c \quad b-a \quad a-a$

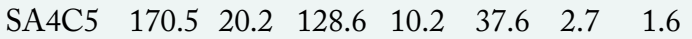
a-b a-ab a-a ab-a a-b b-ab a-a

$\begin{array}{llllllll}\text { SA5C5 } & 155.2 & 15.7 & 99.8 & 13.9 & 33.9 & 2.2 & 1.3\end{array}$ a-abc a-a $\quad a-a b \quad c-b \quad a-b \quad b-b \quad a-a$
TSW BY

DW

HI SOC OY

(g) $\quad\left(\mathrm{kg} \mathrm{ha}^{-1}\right)\left(\mathrm{kg} \mathrm{ha}^{-1}\right) \quad(\%) \quad$ (\%) $\quad\left(\mathrm{kg} \mathrm{ha}^{-1}\right)$

$\begin{array}{lllllllll}25.3 & 215.9 & 26.2 & 32.1 & 1,951.0 & 317.9 & 14.2 & 31.3 & 99.4\end{array}$ c-c $\quad c-b \quad a-a \quad a-a b \quad a-a \quad a-a \quad a-a \quad a-a \quad a-a$

$\begin{array}{lllllllll}23.7 & 213.3 & 22.2 & 32.8 & 2,116.0 & 334.4 & 15.3 & 32.2 & 107.6\end{array}$ b-b bc-c a-a a-a b-a ab-a ab-a ab-a b-a

$\begin{array}{lllllllll}23.7 & 211.8 & 41.5 & 40.7 & 2,389.3 & 331.6 & 16.4 & 32.9 & 109.1\end{array}$ b-b ab-b b-b b-b c-a $\quad$ ab-a $\quad$ c-ab b-ab b-a $\begin{array}{lllllllll}22.8 & 209.3 & 50.8 & 43.5 & 2,441.7 & 346.7 & 17.0 & 33.1 & 114.5\end{array}$ a-b a-b $\quad$ c-c $\quad$ b-b $\quad$ c-a $\quad$ b-a $\quad$ a-ab b-ab b-a $\begin{array}{lllllllll}24.1 & 212.7 & 41.6 & 40.8 & 2,428.3 & 334.0 & 15.8 & 33.4 & 108.0\end{array}$ b-ab abc b-b b-ab c-a ab-a abc-a ab-a b-a $\begin{array}{lllllllll}26.0 & 215.6 & 30.9 & 37.0 & 2,021.0 & 319.6 & 14.2 & 31.4 & 100.4\end{array}$ b-b b-b a-ab a-c a-ab a-a a-a a-ab a-a $\begin{array}{lllllllll}24.8 & 211.1 & 42.5 & 40.0 & 2,428.3 & 350.0 & 15.4 & 31.4 & 111.6\end{array}$ a-a ab-c b-c ab-a b-b ab-a b-a ab-a ab-a $\begin{array}{lllllllll}24.7 & 210.9 & 30.8 & 39.0 & 2,567.0 & 351.3 & 16.2 & 31.9 & 115.1\end{array}$ a-b ab-b a-a ab-b bc-ab ab-a b-ab c-a b-a $\begin{array}{lllllllll}24.9 & 207.6 & 40.6 & 42.1 & 2,629.7 & 377.7 & 17.2 & 32.8 & 123.8\end{array}$ a-b $\quad$ a-b $\quad$ b-b $\quad$ b-ab $\quad$ c-a $\quad$ b-b $\quad$ c-ab c-a $\quad$ b-a $\begin{array}{lllllllll}24.3 & 210.3 & 39.0 & 47.9 & 2,477.7 & 364.5 & 15.7 & 32.8 & 117.9\end{array}$ a-bc ab-b b-b c-c bc-ab b-a b-a a-a b-ab $\begin{array}{lllllllll}24.5 & 210.3 & 29.5 & 37.5 & 2,322.3 & 378.6 & 15.4 & 32.4 & 122.1\end{array}$ 24.54 d-a a-a ab-c a-bc a-c $\quad$ a-a $\begin{array}{lllllllll}24.7 & 204.9 & 32.2 & 34.2 & 2,523.7 & 389.5 & 16.3 & 32.3 & 128.3\end{array}$ b-a c-a b-b a-a a-b a-c ab-a a-b ab-c $\begin{array}{lllllllll}23.2 & 201.7 & 31.9 & 40.0 & 2,824.7 & 435.7 & 17.4 & 33.0 & 144.3\end{array}$ a-a ab-a c-a ab-b a-b a-c $\quad a c-b \quad a b-b \quad c-c$ $\begin{array}{lllllllll}23.6 & 199.4 & 41.8 & 42.2 & 2,744.7 & 422.2 & 17.9 & 33.1 & 140.1\end{array}$ a-b a-a b-b ab-ab a-a a-c $\quad$ c-b ab-ab c-b $\begin{array}{lllllllll}24.5 & 204.0 & 40.9 & 44.9 & 2,715.0 & 413.3 & 16.4 & 33.2 & 134.3\end{array}$ b-bc bc-a b-b b-bc a-ab a-b abc-a b-ab ab-b $\begin{array}{lllllllll}25.5 & 209.6 & 36.5 & 36.5 & 2,349.3 & 346.6 & 14.8 & 32.5 & 111.1\end{array}$ b-a d-a a-c a-bc a-c a-b a-a ab-a a-c $\begin{array}{lllllllll}25.0 & 204.9 & 46.7 & 40.3 & 2,876.7 & 374.1 & 15.5 & 32.1 & 122.0\end{array}$ b-c ab-a b-c b-a b-c bc-bc ab-a a-ab bc-bc $\begin{array}{lllllllll}24.8 & 201.7 & 41.8 & 38.5 & 3,105.7 & 380.5 & 16.5 & 32.6 & 124.4\end{array}$ b-a ab-a ab-b Ab-b Bc-c c-b ac-ab bc-ab c-b $\begin{array}{lllllllll}23.7 & 199.4 & 36.6 & 36.0 & 3,436.3 & 359.6 & 17.4 & 32.7 & 118.5\end{array}$ a-a $\quad$ a-a $\quad$ a-ab $\quad$ a-a $\quad c-b \quad a b-a b \quad c-a b \quad b a-a \quad b-a$ $\begin{array}{lllllllllll}123.7 & 10.1 & 25.1 & 202.7 & 40.4 & 45.9 & 2,910.3 & 346.6 & 15.8 & 33.0 & 111.8\end{array}$ c-c a-ab b-c $\quad$ bc-a $a b-b \quad c-c \quad b-b \quad a-a \quad a b-a \quad a b-a \quad a-a$ $\begin{array}{lllllllllll}123.8 & 10.6 & 23.2 & 215.9 & 25.6 & 31.3 & 2,395.3 & 333.6 & 14.0 & 32.0 & 106.6\end{array}$

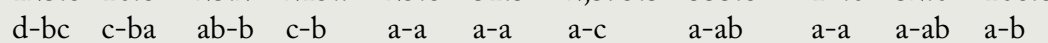

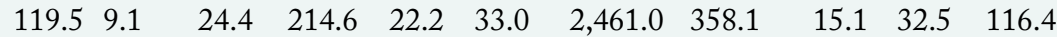
b-a b-a c-a bc-d a-a ab-a bc-b a-ab a-a ab-ab abc-ab $\begin{array}{lllllllllll}116.7 & 8.0 & 22.8 & 211.3 & 29.1 & 32.7 & 2,578.3 & 374.2 & 16.1 & 33.3 & 124.5\end{array}$ b-a a-a ab-b a-b a-a ab-a bc-ab b-b a-a b-ab c-b $\begin{array}{lllllllllll}121.3 & 9.5 & 24.1 & 208.7 & 31.5 & 36.5 & 2,707.7 & 351.4 & 16.5 & 33.8 & 118.9\end{array}$ c-b b-ab bc-b a-b a-a b-a c-a $\quad$ a-a $\quad$ a-a $\quad$ b-b $\quad$ bc-a

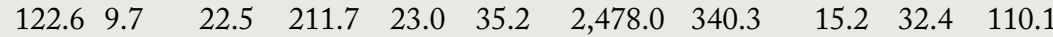
c-c $\quad$ bc-a a-a $a b-b \quad a-a$ ab-a $\quad$ bc-ab a-a $\quad$ a-a ab-a ab-a

Note: Number followed the same characters in column and row were not significant by DMRT a: 0.05\%; PH: Plant Height; NL: Number of the Leaf, LA: Leaf Area; NPB: Number of Primary Branch; NSB: Number of Secondary Branch; HD: Head Diameter; ST: Stem Thickness; DFI: Days to Flowering Initiative; DFM: Days to Flowering Maturity; DCM: Days Crops Maturity; NSP: Number of Seed per plant; TSW: Total of 1000 Seed Weight; FW: Fresh Weight; CFD: Capitulum Filling Days; DW: Dry Weight; HI: Harvest Index \%; SOC: Seed Oil Content; OY: Oil Yield. 
of the crop. All physiological events in plants, i.e., ion uptake, membrane permeability, stomata conductance, mitochondrial respiration, stomata closure, solutes transportation, growth, and photosynthesis rate, were directly or indirectly affected by the salicylic acid application. It has been witnessed that the salicylic acid (SA) has increased the number of leaves on a plant, promoted the vegetative growth by increasing the number of leaves in plants of strawberry $(0.25-$ 0.5mM), (Rivas-San Vicente and Plasencia, 2011) observed similar results that, SA boosted up vegetative growth cycle and physiological processes of plants under drought conditions. Leaf area is a significant growth and productivity determining influencing factor for crop production because it affects leaf and chloroplast structure, which ultimately increases the rate of photosynthesis (Rivas-San Vicente and Plasencia, 2011; Cai et al., 2015). The simulation result of the combined model for shade and sunlight has significantly influenced canopy carbon and leaf variability adaptively in an extreme environment (Plant Genome Editing with CRISPR Systems, 2019).

The present study showed significant interaction among safflower cultivars and frequent application levels of SA for leaf area. This has also promoted growth and enzyme activities with increase chlorophyll pigment production, provided support to protein synthesis and total non-structural carbohydrates, which increased the plant leaf area. This attained leaf area (LA) started decreasing but abruptly increased in all the treatments, this variation could be due to the senescence of the older leaves in response to drought conditions. A lower specific leaf area of SA treated wheat plants under stress conditions. Anti-senescence effect on plant organs, prolonged vegetative growth leading towards a higher leaf area has been witnessed (Espanany et al., 2016). Applied Salicylic Acid either with seed soaked (SS) or soil incorporated (SI), exogenously, could increase plant growth in all the stress conditions significantly. Prestress foliar application of SA protects water-stress against oxidative damage at $2.0 \mathrm{~mm}$ concentration (Faize and Faize, 2018).

Generally, moisture deficiency lowers the potential yield by imparting a negative impact on crop growth and the number of primary branches but then, SA application might have an ameliorating effect on the number of primary branches and influenced secondary branched to produce ultimate vegetative growth yield (Table 3 ). The results are in agreement with the findings of (Mahasi et al., 2006) as they reported SA application increases, a range of 5-10 branches for spine cultivars, and 10-16 branches for spineless cultivars. The result showed that the maximum numbers of primary branches were found in plants treated with salicylic acid. The Salicylic acid increased branches in mustard (Klemme et al., 2019), reproductive growth effectively and ensured maximum flowers leading towards the increased number of heads (Reddy and Sharma, 2016).

Exogenous application of salicylic acid improved the leaf area, formed the highest number of leaf area, and increased the nitrogen use efficiency and chlorophyll content. It regulates the polyphenol oxidase (PPO), which leads to generating more primary branches that ultimately caused secondary branches to increase under SA3, SA4 concentration. It has been widely accepted that more the primary branches, more will be the secondary branches assuring the higher number of seed heads on a plant. The SA $(0.3 \mathrm{~mm}$, $0.5 \mathrm{~mm}$ ) produced the maximum number of branches in mustard (Klemme et al., 2019). The maximum numbers of primary branches were the straight signal of the higher number of secondary branches and maximum number of heads (Table 3). The increased size of stem diameter is a sign of increased vegetative growth, more lateral branches, more flowers, and more leaves. It has also been revealed the $\mathrm{SA}$ increases the fresh weight of the shoot and roots (Baghizadeh, 2011; Islam et al., 2018). Previously revealed findings confirm the findings of present study. SA helps the plants for their effective response to changing environment. Hence, it can perform as a plant growth regulator for improving the plant's growth and stimulating the gradient of mineral nutrients under abiotic stress conditions (Hernández-Ruiz and Arnao, 2018).

In the present study, SA3 and SA4 applications significantly reduced the number of days to flowering compared with other treatments (Figure 1). In response to SA, a lesser number of days for flowering and the highest flowering percentage was recorded with increased spike length, size, and the number of florets in barley crops (Bandurska and Stroiński, 2005). Salicylic acid can start early flowering in plants of strawberry by decreasing the days required for opening the flowers. (Hayat et al., 2010) In this study, 
$\mathrm{C} 2$ and $\mathrm{C} 1$ exhibited earlier flowering at treatment SA4 $(0.75 \mathrm{~mm})$. Salicylic Acid regulates the activities of various enzymes such as superoxide dismutase (SOD) and phenylalanine ammonia-lyse (PAL), which are the main components for inducing plant physiological mechanism along with self-defense system against biotic and abiotic stresses (Janda et al., 2014). The SA at $0.5 \mathrm{mM}, 0.75 \mathrm{~mm}$, and $1.00 \mathrm{~mm}$ resulted in time-saving under stress and extreme weather conditions. These findings (Figure 2).

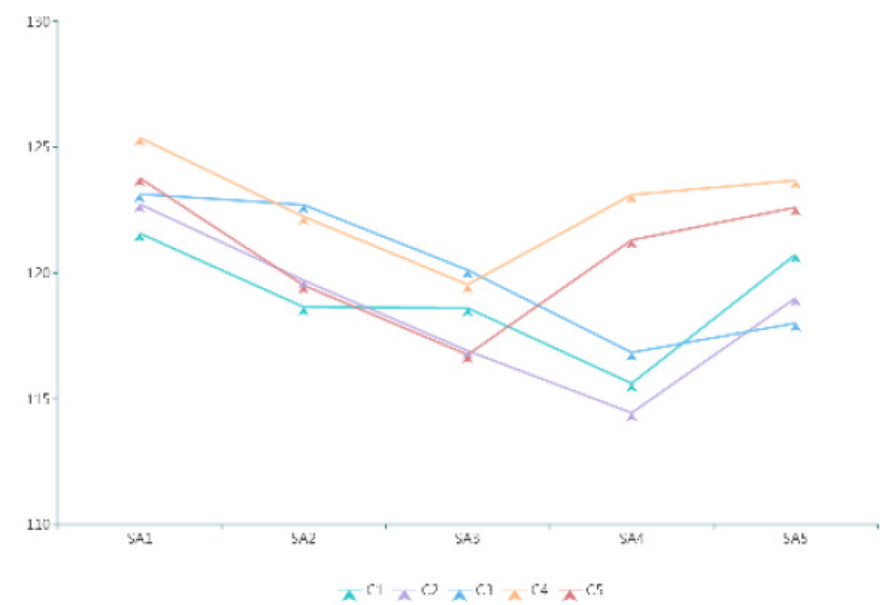

Figure 1: Phenotypic plasticity of days taken flowering initiation from seed of spineless safflower (Carthamus tinctorius L.) cultivars in response to exogenous application of salicylic acid under rainfed climate condition (SE: 0.295 LSD).

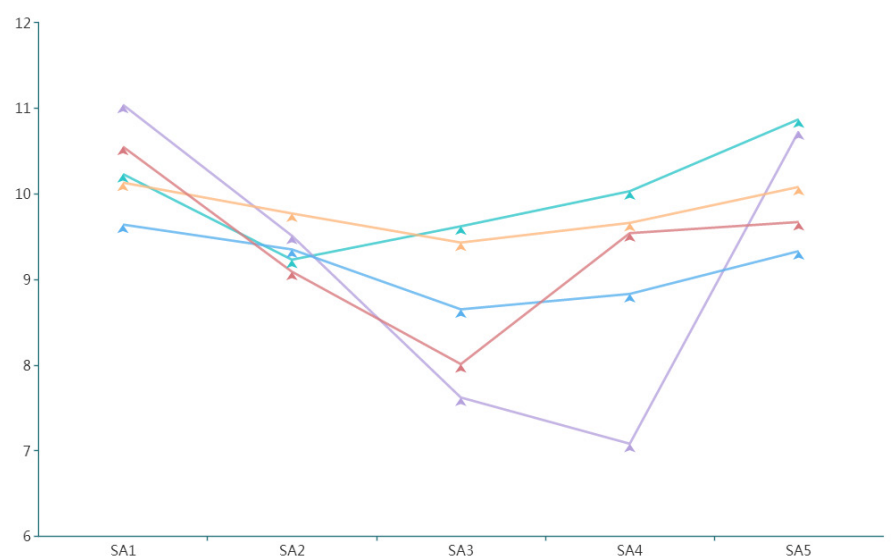

$\pi^{C 1} \pi^{C 2} \pi^{C 3} \pi^{C 4} \pi^{C 5}$

Figure 2: Phenotypic plasticity of days taken flowering maturity from seed of safflower (Carthamus tinctorius L.) cultivars in response to exogenous application of salicylic acid under rainfed conditions (SE: 0.148 LSD).

The particular mechanism of flower inducing property of SA is yet to be explored. The capitulum filling duration and the total number of days required for the crop maturity (Figures 3 and 4) were significantly decreased by the SA foliar spray. Numerous physiological and biological effects of salicylic acid on plant growth and development were reported to induce early flower maturity because it regulates the physiological actions, i.e., ion uptake, membrane permeability, mitochondrial respiration, closure of stomata and solute transport (Cai et al., 2015). Different plants ensure early flowering as a result of foliar application of SA, and historical evidences verify the claims of the present study (Wani et al., 2017). Foliar spray $(0.25 \mathrm{~mm}$ and $0.5 \mathrm{~mm})$ of the aqueous concentration of salicylic acid on African violet produced the maximum number of leaves per plant, flowers and reduced the number of days taken to flower induction, capitulum filling process and days taken to crop maturity as well, in comparison with control condition plots.

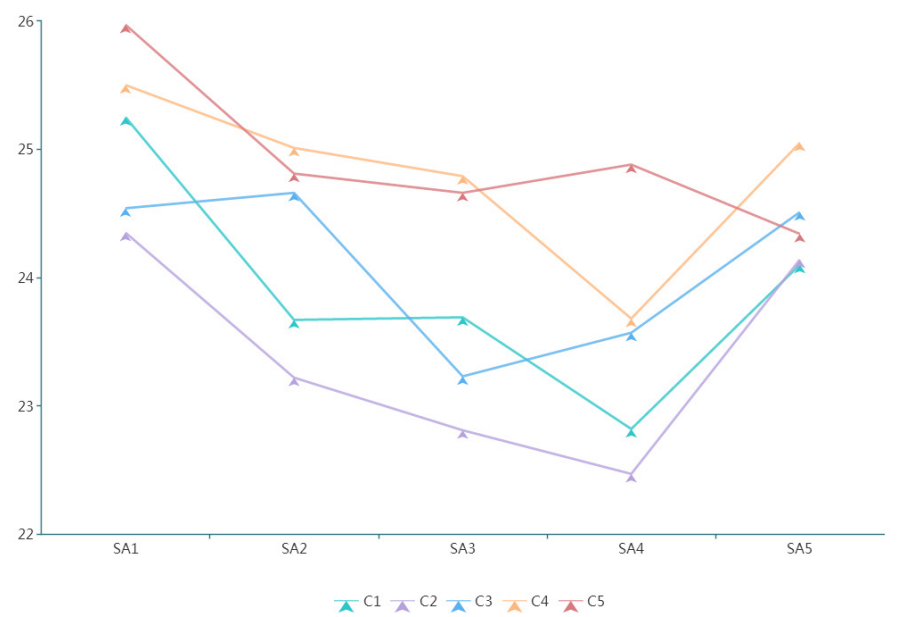

Figure 3: Phenotypic plasticity of capitulum filling duration of safflower (Carthamus tinctorius L.) cultivars in response to exogenous application of salicylic acid under rainfed climate conditions (SE: 0.180 LSD).

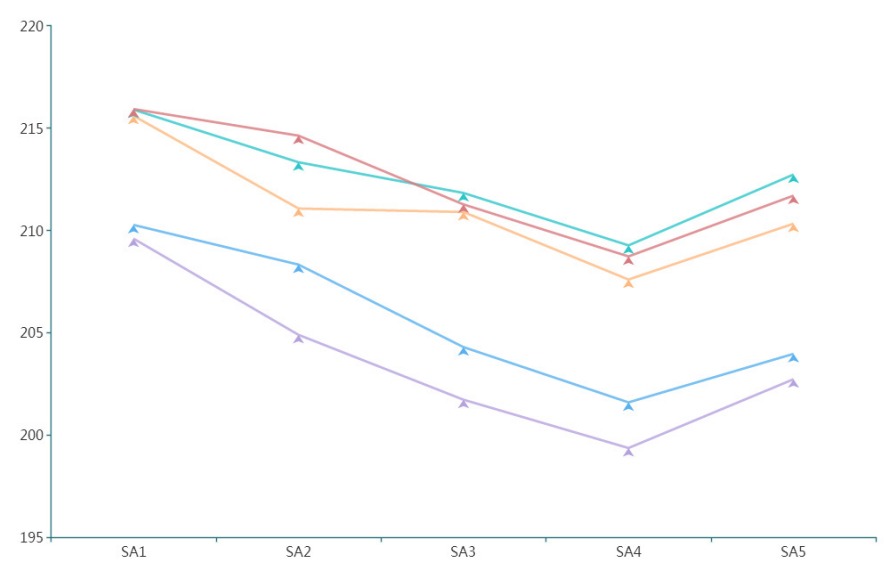

$\pi^{\mathrm{C} 1} \pi^{\mathrm{C} 2} \pi^{\mathrm{C} 3} \pi^{\mathrm{C} 4} \pi^{\mathrm{C} 5}$

Figure 4: Phenotypic plasticity of number of days taken complete crop maturity starts from seed of safflower (Carthamus tinctorius L.) cultivars in response to exogenous application of salicylic acid under rainfed climate conditions (SE: 0.320 LSD).

Foliar spray of SA imparts a positive impact on crop yield through efficient translocation of photosynthesis, and it contributed in cell wall rigidity which in turn 
improves light interception and photosynthetic efficiency, and thus crop yield parameters comparable the number of head, seed, weight, and oil quantity and quality (Kabiri et al., 2014; Cai et al., 2015). High efficiency of vegetative and reproductive growth parameters ultimately contributed to maximum high-quality seed yield and oil recovery. One of the yield components of safflower is the number of seeds plant $^{-1}$. The number of seed plant ${ }^{-1}$ and its quality play an essential role in crop productivity and profits. The result of the present research showed (Figure 5) interaction between the level of treatment factors expecting to increase productivity and oil quality (Figure 6) of safflower under changing environment and extreme weather events. The rate of phonological development could increase at a warm temperature, and the significant impact was during the reproductive stage (Bange and Milroy, 2004; Hatfield and Prueger, 2015). Salicylic acid promotes the number of grains in barley and increased total crop yield. LarqueSaavedra and (Martín-Mex et al., 2015), astonishingly observed the same significant increase in yield of cucumber and tomato as found by the present study. Congruent results were also obtained by (Bandurska and Stroiński, 2005) in barley. Salicylic acid when applied at the rate of $100 \mathrm{ppm}$ through foliar spray method, enhances the flower weight and quality, which directly lead towards the increase in individual seed weight. These results conform to the findings of (Muthulakshmi and Lingakumar, 2017) they observed significant differences for 100 achene weight in sunflower by combined application of salicylic acid with silicic acid $(0.5 \mathrm{~mm}, 0.25 \mathrm{~mm})$ levels.

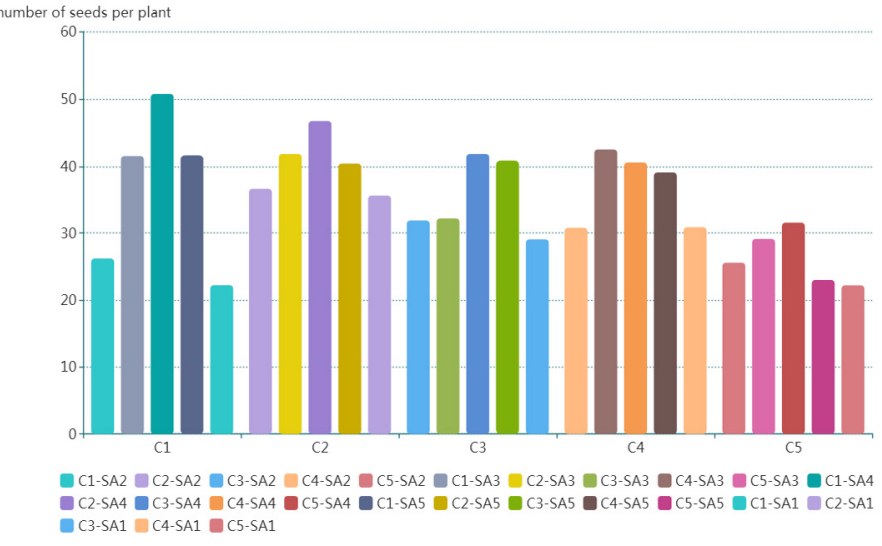

Figure 5: Phenotypic plasticity of number of seeds plant ${ }^{-1}$ of spineless saflower (Carthamus tinctorius L.) cultivars in response to exogenous application of salicylic acid under rainfed climate conditions (SE: 0.721 LSD).

The optimum application of salicylic acid regulated physiological processes and rapid safflower leaf growth and leaf area to intercept more solar radiation, resulting in efficient photosynthesis and while enhancing the leaf number and their surface area, more branches, heads and seeds on a plant, enhanced diameter of stem and head besides inducing resistance in plants against extreme weather events. The biological yield was calculated lower in untreated plots (Table 3), as we found that the seed yield in soybean was increased with SA spray. The significant increase in seed yield when castor bean was sprayed with salicylic acid. The acceptable application of SA enabled the plants to produce rapid leaf growth and more leaf area to intercept more solar radiation, making the photosynthetic mechanism more efficient and thus produced more seed yield plants.

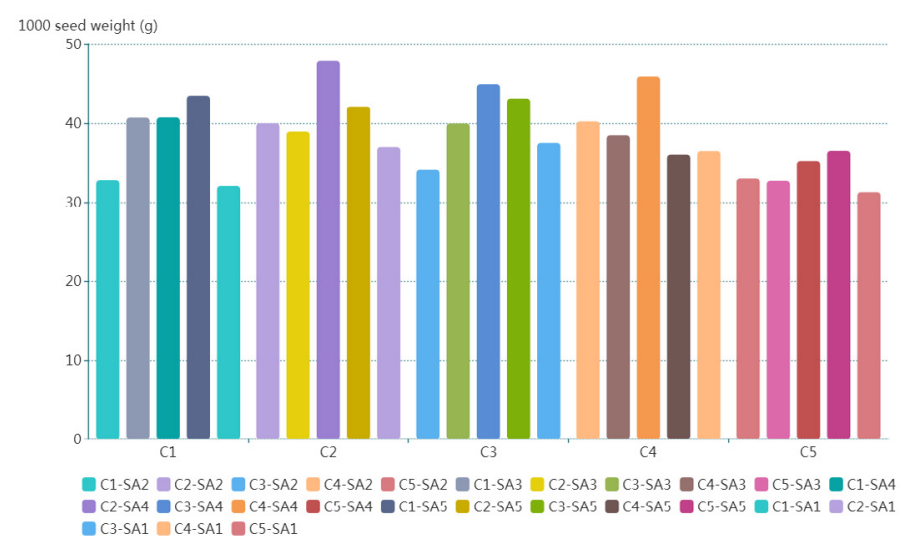

Figure 6: Phenotypic plasticity of 1000 seed weight $(g)$ spineless safflower (Carthamus tinctorius L.) cultivars in response to exogenous application of salicylic acid under rainfed climate conditions (SE: 0.614 LSD).

The ability to change the dry matter into economic yield was positively influenced by the optimum concentration of salicylic acid to ensure good economic yield (Table 2). (Nazar et al., 2011) also favor our claims based on their findings on castor bean, and barley experiments. Oil yield mainly depends on obtained yield and oil recovery (\%) in the seed plant ${ }^{-1}$, and our results (Figures 6 and 7) are in line with it. SA applications have enhanced seed oil content (\%) and oil yield $\left(\mathrm{kg} \mathrm{ha}^{-1}\right)$ in this research. Genetic differences for obtained yield also affect oil yield from a plant in oilseed crops. Present experimentation results are in accordance with the findings of (Cleland and Tanaka, 1979; Muthulakshmi and Lingakumar, 2017) concluded that the inclusion of salicylic acid spray has resulted in a significant increase in the oil yield of the castor-bean crop. The salicylic acid spray has increased the physiological and biological functioning of plant cells under changing the climate, and it impacted positively for all the vegetative and 
reproductive stages of the crop. The salicylic acid is the direct indication of an increase in oil quantity and quality because SA positively regulated floret and seed development processes (Abreu and MunnéBosch, 2009) reported $1-2 \mathrm{mmol} / \mathrm{l}$. SA was the most effective with a decrease in treatment time.

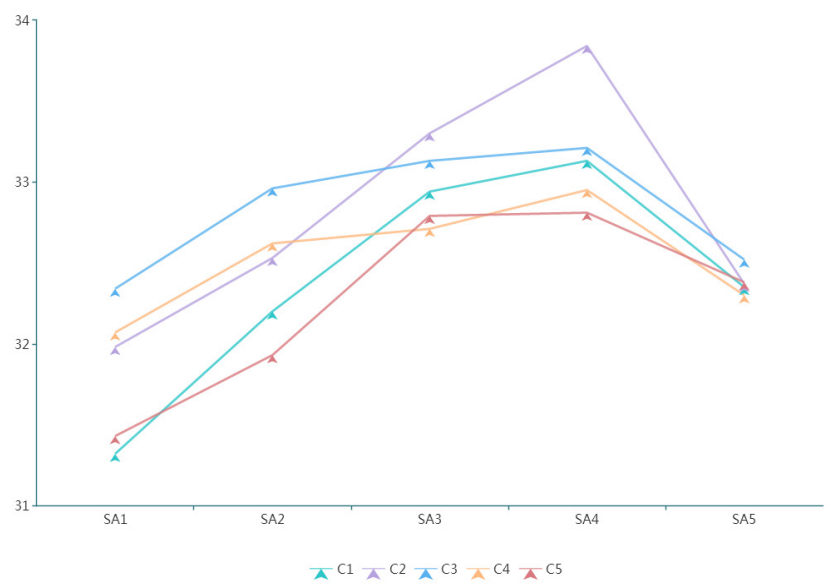

Figure 7: Phenotypic plasticity of seed oil content (\%) of spineless safflower (Carthamus tinctorius L.) cultivars in response to exogenous application of salicylic acid under rainfed climate conditions (SE: 0.247 LSD).

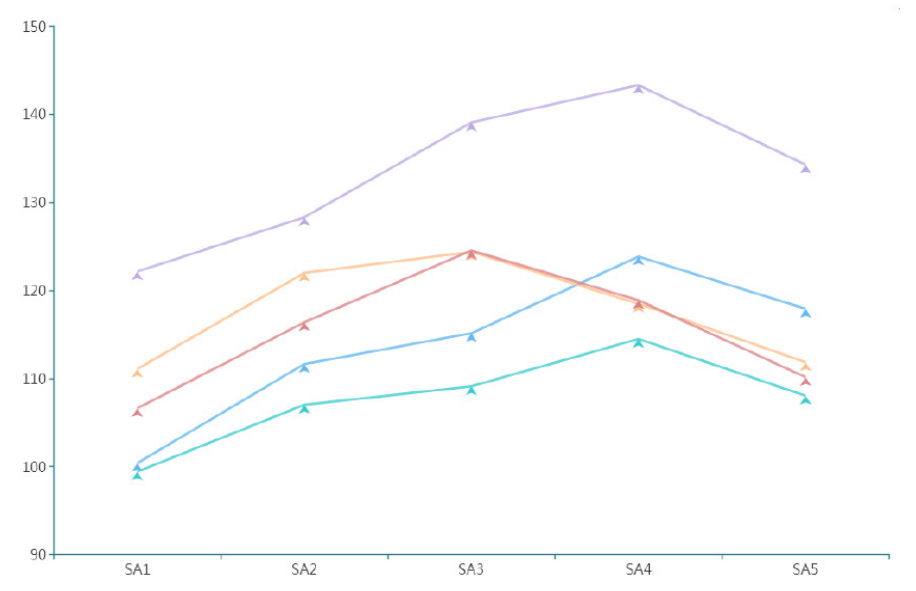

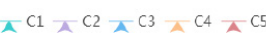

Figure 8: Phenotypic plasticity of oil yield $\left(\mathrm{kg} \mathrm{ha}^{-1}\right)$ of spineless safflower (Carthamus tinctorius L.) cultivars in response to exogenous application of salicylic acid under rainfed climate conditions (SE: 0.873 LSD).

Safflower spineless cultivars $\mathrm{C} 2$ and $\mathrm{C} 3$ under treatment SA3 and SA4 produced $2 \%$ higher oil content compared with other plots; these results (Figures 6 and 7) are in agreement with (Shirzadeh and Kazemi, 2012; Pai et al., 2014). As a secondary metabolite, salicylic acid in minor concentration plays an essential role in the regulation of plant growth and development in response to abiotic stresses (Muthulakshmi and Lingakumar, 2017). Safflower oil is a capable source for biodiesel production. Hence, promoting safflower production in rain-fed regions could be a better option of future clean energy production.

The overall performance of C2 (L16378) was consistent and most effective for all studied parameters. Fewer damages were noticed for safflower crop under extreme climatic events,i.e.,hail storming and drought, compared with wheat and barley crop. The present study outcome mentioned that the foliar application of salicylic acid had ameliorated the negative impacts of extreme events such as prolonged drought through enhanced stem thickness, root growth, efficient photosynthesis, head diameter, early flowering induction, early maturity, and reduced total crop duration.

Spineless safflower (Carthamus Pistorius L.) as easy and a multipurpose crop appears as a promising alternative due to its acclimatization to fluctuating weather and high potential value as an oilseed crop under rain-fed conditions. Safflower can be a candidate crop in rain-fed agro-ecosystem due to its potential for growth and development under extreme temperature and the economic value in terms of both oil and seed and significant economic impact. It would be considered as the right choice for evaluating drought risk adaptation.

\section{Conclusions and Recommendations}

Present research experiment indicated that SA helps safflower cultivars to cope better with environmental changes and drought effects. This fact is supported by the expressions of the critical concentration of salicylic acid foliar application $0.75 \mathrm{mM}$ (SA4) to promote higher productivity in acclimating extreme weather change. The most responsive safflower cultivar was $\mathrm{C} 3$ (L26748), showing higher head diameter, dry weight, fresh weight, harvest index, oil yield, oil content, stem thickness, early maturity. Spineless safflower cultivars could acclimatize to a wide range of extreme weather with salicylic acid treatment to ensure sustainable agriculture in rain-fed regions. Further research work on the onset of extreme weather events in agriculture is required to obtain more information about how SA ameliorate drought and hailstorms effects in the field.

\section{Acknowledgments}

We acknowledge the institutional and technical support of Prof. Dr. Fayyaz-ul-Hassan, dean Faculty of Agriculture and Crop Sciences, PMAS-Arid Agriculture University Rawalpindi, Pakistan. 
Novelty Statement

Our research evaluated the expressions of the critical concentration of salicylic acid foliar application $(0.75 \mathrm{mM})$ to promote higher productivity in acclimating extreme weather change. The study also categorized utmost responsive spineless safflower cultivar (L26748), resulted in higher oil yield.

\section{Author's Contributions}

The research conceptualization was done by AA and ZA methodology, AA and HQ software and formal analysis, $\mathrm{RS}, \mathrm{AD}$ and $\mathrm{ZZ}$ investigation, $\mathrm{AA}, \mathrm{ZL}$ and $\mathrm{MH}$ resources, $\mathrm{ZA}$ and $\mathrm{ZL}$ data curation, $\mathrm{AA}$ writing original draft preparation, AA review and editing, $\mathrm{ZA}, \mathrm{RS}$ and $\mathrm{ZL}$ visualization, $\mathrm{AA}$ supervision, $\mathrm{ZA}$ and $\mathrm{ZL}$ project administration, $\mathrm{ZL}$ and $\mathrm{FH}$ funding acquisition, $\mathrm{ZL}$ and $\mathrm{FH}$ all authors have read and agreed to the published version of the manuscript.

\section{Funding}

The research work was done under the entitled project "Phenotypic Plasticity of Safflower (Carthamus tinctorius L.) in Response to Environment and Integrated Nutrient Management" of Department of Agronomy. We are also very thankful to Punjab Education Endowment Fund (PEEF) and CSC for their financial support. We also acknowledge the support from the National Key Research and Development Program of China (2018YFD1000901) and Major Scientific and Technological Projects of the XPCC (2018AA00403).

\section{Conflicts of interest}

The authors have declared no conflict of interest.

\section{References}

Abreu, M.E. and S. Munné-Bosch. 2009. Salicylic acid deficiency in NahG transgenic lines and sid2 mutants increases seed yield in the annual plant arabidopsis thaliana. J. Exp. Bot., 60(4): 1261-1271. https://doi.org/10.1093/jxb/ ern363

Afzal, I., S.M.A. Basra, M. Farooq and A. Nawaz. 1560. Alleviation of salinity stress in spring wheat by hormonal priming with ABA, salicylic acid and ascorbic acid. Int. J. Agric. Biol., 8(1): 23-28.
Ahmad, A., M. Ashfaq, G. Rasul, S.A. Wajid, T. Khaliq, F. Rasul, U. Saeed, M.H. ur Rahman, J. Hussain, I. Ahmad Baig, S.A.A. Naqvi, S.A.A. Bokhari, S. Ahmad, W. Naseem, G. Hoogenboom and R.O. Valdivia. 2015. Impact of climate change on the rice wheat cropping system of Pakistan. Handb. Clim. Change Agroecosyst., pp. 219-258. https://doi. org/10.1142/9781783265640_0019

Ahmad, S., G. Abbas, Z. Fatima, R.J. Khan, M.A. Anjum, M. Ahmed, M.A. Khan, C.H. Porter and G. Hoogenboom. 2017. Quantification of the impacts of climate warming and crop management on canola phenology in Punjab, Pakistan. J. Agron. Crop Sci., 203(5): 442-452. https://doi.org/10.1111/jac.12206

Amin,A.,W.Nasim,M.Mubeen, S. Sarwar,P.Urich, A. Ahmad, A. Wajid, T. Khaliq, F. Rasul, H.M. Hammad, M.I.S. Rehmani, M. Mubarak, N. Mirza, A. Wahid, S. Ahamd, S. Fahad, A. Ullah, M.N. Khan, A. Ameen, B. Shahzad, S. Saud, H. Alharby, S.T. Ata-Ul-Karim, M. Adnan, F. Islam and Q.S. Ali. 2018. Regional climate assessment of precipitation and temperature in Southern Punjab (Pakistan) using SimCLIM climate model for different temporal scales. Theor. Appl. Climatol., 131: 121-131. https:// doi.org/10.1007/s00704-016-1960-1

Amin, A., W. Nasim, M. Mubeen, A. Ahmad, M. Nadeem, P.Urich, S. Fahad, S. Ahmad, A.Wajid, F. Tabassum, H.M. Hammad, S.R. Sultana, S. Anwar, S.K. Baloch, A. Wahid, C.J. Wilkerson and G. Hoogenboom. 2018a. Simulated CSMCROPGRO-cotton yield under projected future climate by SimCLIM for southern Punjab, Pakistan. Agric. Syst., 167: 213-222. https://doi.org/10.1016/j.agsy.2017.05.010

Arshad, A., K. Yousaf, Q. Hua, L. Ming, W. Zhang and A.M.U.H. Mateen. 2019. Impact of climate change on apple and mango production in China and Pakistan. Tech. Sess. Proc. Int. Hortic. Conf., pp.121.

Ashraf, A., S.S. Ristina, M. Asad, M. Hasan, H. Qamar, M. Mudassar, M. Raza, W. Anum, W. Abbasi and A. Arshad. 2019. Variability and correlation study of different newly developed sunflower hybrids in Pakistan. Int. J. Biosci., 14(2): 398-40.

Aydın, F. and H. Sarptaş. 2018. The impact of the climate change to crop cultivation: the case study with model crops for Turkey. Pamukkale 
Univ. J. Eng. Sci., 24(3): 1232-1241. https://doi. org/10.5505/pajes.2017.37880

Baghizadeh, A., 2011. The salicylic acid effect on the tomato (Lycopersicum esculentum Mill.) sugar, protein and proline contents under salinity stress $(\mathrm{NaCl})$. J. Biophys. Struct. Biol., 2(3): 35-41.

Bandurska, H. and A. Stroiński. 2005. The effect of salicylic acid on barley response to water deficit. Acta Physiol. Plant, 27: 379-386. https://doi. org/10.1007/s11738-005-0015-5

Bange, M.P. and S.P. Milroy. 2004. Impact of short-term exposure to cold night temperatures on early development of cotton (Gossypium birsutum L.). Aust. J. Agric. Res., 55(6): 655664. https://doi.org/10.1071/AR03221

Cai, H., M. He, K. Ma, Y. Huang and Y. Wang. 2015. Salicylic acid alleviates cold-induced photosynthesis inhibition and oxidative stress in Jasminum sambac. Turk. J. Biol., 39: 241-247. https://doi.org/10.3906/biy-1406-35

Canvin, D.T., 1965. The effect of temperature on the oil content and fatty acid composition of the oils from several oil seed crops. Can. J. Bot., 43(1): 63-69. https://doi.org/10.1139/b65-008

Cisse, A., A. Arshad, X. Wang, F. Yattara, Y. Hu, A. Cisse, A. Arshad, X. Wang, F. Yattara and Y. Hu. 2019. Contrasting impacts of longterm application of biofertilizers and organic manure on grain yield of winter wheat in North China Plain. Agronomy, 9: 312. https://doi. org/10.3390/agronomy9060312

Cleland, C.F. and O. Tanaka. 1979. Effect of daylength on the ability of salicylic acid to induce flowering in the long-day plant lemna gibba G3 and the short-day plant lemna paucicostata 6746 . Plant Physiol., 64(3): 421424. https://doi.org/10.1104/pp.64.3.421

Edenhofer, O., Y. Pichs-Madruga, E. Sakona, S. Farahani, K. Kadner, A. Seyboth, I. Adler, S. Baum, P. Brunner and B. Eickemeier. 2014. IPCC, 2014: Summary for Policymakers. Climate change 2014: Mitigation of climate change. Contribution of working group III to the fifth assessment report of the intergovernmental panel on climate change. www.ipcc.ch

Espanany, A., S. Fallah and A. Tadayyon. 2016. Seed priming improves seed germination and reduces oxidative stress in black cumin (Nigella sativa) in presence of cadmium. Ind. Crops Prod., 79: 195-204. https://doi.org/10.1016/j. indcrop.2015.11.016

Faize, L. and M. Faize. 2018. Functional analogues of salicylic acid and their use in crop protection. Agronomy, 8(1): 5. https://doi.org/10.3390/ agronomy 8010005

Government of Pakistan (GOP), 2016. Agricultural Statistics of Pakistan 2016/17. 2018.

Gupta, V., S. Liu, H. Ando, R. Ishii, S. Tateno, Y. Kaneko, M.Yugami, S. Sakamoto, Y.Yamaguchi, O. Nureki and H. Handa. 2013. Salicylic acid induces mitochondrial injury by inhibiting ferrochelatase heme biosynthesis activity. Mol. Pharmacol., 84(6): 824-833. https://doi. org $/ 10.1124 / \mathrm{mol} .113 .087940$

Hatfield, J.L. and J.H. Prueger. 2015. Temperature extremes: Effect on plant growth and development. Weather Clim. Extrem., 10: 4-10. https://doi.org/10.1016/j.wace.2015.08.001

Hayat, Q., S. Hayat, M. Irfan and A. Ahmad. 2010. Effect of exogenous salicylic acid under changing environment: A review. Environ. Exp. Bot., 68(1): 14-25. https://doi.org/10.1016/j. envexpbot.2009.08.005

Hernández-Ruiz, J. and M.B. Arnao. 2018. Relationship of melatonin and salicylic acid in Biotic/Abiotic plant stress responses. Agronomy, 8(4): 33. https://doi.org/10.3390/ agronomy 8040033

Hussain, M.I. and A.J. Al-Dakheel. 2018. Effect of salinity stress on phenotypic plasticity, yield stability, and signature of stable isotopes of carbon and nitrogen in safflower. Environ. Sci. Pollut. Res., 25(24): 23685-23694. https://doi. org/10.1007/s11356-018-2442-z

Hussain, S., F. Khan,H.A.Hussain and L. Nie.2016. Physiological and biochemical mechanisms of seed priming-induced chilling tolerance in rice cultivars. Front. Plant Sci., 7: 116. https://doi. org/10.3389/fpls.2016.00116

Imran, M.A., A. Ali, M. Ashfaq, S. Hassan, R. Culas and C. Ma. 2018. Impact of Climate Smart Agriculture (CSA) practices on cotton production and livelihood of farmers in Punjab, Pakistan. Sustainable, 10: 2101. https://doi. org/10.3390/su10062101

IPCC Special Report 1.5 -Summary for Policymakers 2018. Global warming of $1.5^{\circ} \mathrm{C}$. An IPCC Special Report on the impacts of global warming of $1.5^{\circ} \mathrm{C}$ above pre-industrial levels and related global greenhouse gas emission pathways, in the context of strengthening the 
global response to the threat of climate change. www.ipcc.ch

IPCC, 2014. Climate chage 2014: Impacts, adaptation, and vulnerability summary for policymakers. www.ipcc.ch

Islam, M.Z., M.A. Mele, K.Y. Choi, J.P. Baek and H.M. Kang. 2018. Salicylic acid in nutrient solution influence the fruit quality and shelf life of cherry tomato grown in hydroponics. Sains Malaysiana, 14: 537-542. https://doi. org/10.17576/jsm-2018-4703-14

Janda, T., O.K. Gondor, R. Yordanova, G. Szalai and M. Pál. 2014. Salicylic acid and photosynthesis: signalling and effects. Acta Physiol. Plant, 36: 2537-2546. https://doi.org/10.1007/s11738014-1620-y

Kabiri, R., F. Nasibi and H. Farahbakhsh. 2014. Effect of exogenous salicylic acid on some physiological parameters and alleviation of drought stress in Nigella sativa plant under hydroponic culture. Plant Protect. Sci., 50: 4351. https://doi.org/10.17221/56/2012-PPS

Klemme,S.,Y.De Smet, B.P.A.Cammue and M.De Block. 2019. Selection of salicylic acid tolerant epilines in brassica napus. Agronomy, 9(2): 92. https://doi.org/10.3390/agronomy9020092

Lovelli, S., M. Perniola, A. Ferrara and T. Di Tommaso. 2007. Yield response factor to water (Ky) and water use efficiency of Carthamus tinctorius L. and Solanum melongena L. Agric. Water Manage., 92(1-2): 73-80. https://doi. org/10.1016/j.agwat.2007.05.005

Mahasi, M.J., R.S. Pathak, F.N. Wachira, T.C. Riungu, M.G. Kinyua and J.W. Kamundia. 2006. Correlations and path coefficient analysis in exotic safflower (Carthamus tinctorious L.) genotypes tested in the arid and semi arid lands (Asals) of Kenya. Asian J. Plant Sci., 5(6): 1035-1038. https://doi.org/10.3923/ ajps.2006.1035.1038

Martín-Mex, R., Á. Nexticapan-Garcéz, E. Villanueva-Couoh, V. Uicab-Quijano, S. Vergara-Yoisura and A. Larqué-Saavedra. 2015. Salicylic acid stimulates flowering in micropopagated gloxinia plants. Rev. Fitotec. Mex.,38(2):115-118.https://doi.org/10.35196/ rfm.2015.2.115

Muthulakshmi, S. and K. Lingakumar. 2017. Role of salicylic acid (SA) in plants. A review. Int. J. Appl. Res., 3(3): 33-37.

Nasim, W., A. Amin, S. Fahad, M. Awais, N.
Khan, M. Mubeen, A. Wahid, M.H. Rehman, M.Z. Ihsan, S. Ahmad, S. Hussain, I.A. Mian, B. Khan and Y. Jamal. 2018. Future risk assessment by estimating historical heat wave trends with projected heat accumulation using SimCLIM climate model in Pakistan. Atmos. Res., 205: 118-133. https://doi.org/10.1016/j. atmosres.2018.01.009

Nazar, R., N. Iqbal, S. Syeed and N.A. Khan. 2011. Salicylic acid alleviates decreases in photosynthesis under salt stress by enhancing nitrogen and sulfur assimilation and antioxidant metabolism differentially in two mungbean cultivars. J. Plant Physiol., 168(8): 807-815. https://doi.org/10.1016/j.jplph.2010.11.001

OECD-FAO Agricultural Outlook, OECD Agriculture statistics (database). 2016. http:// dx.doi.org/10.1787/888933381602

Pai, V., M.A. Yeganeh, E. Hadavi, M. Kalhori, A. Valentyn, P. Thavong, D.D. Archbold, T. Pankasemsuk, R. Koslanund, N. Thakur, M. Gharezi, N. Joshi, E. Sadeghian, A. Wali, S.S. Khan, Z. Hussian, A. Lichter, M.C. Peppi, G. Vitis, B. Sefid, S.Y. Wang, W. Zheng, J. Song, L. Fan, C. Forney, L. Campbell-Palmer, S. Fillmore, T.L. Oswald, V.P. Deepthi, J. Strydom, A.D. Al-Qurashi, M.A. Awad, S.K. Jawandha, N. Gupta and J.S. Randhawa. 2014. Effect of Salicylic Acid on Storage Life and Postharvest Quality of Oilseeds. $1^{\text {st }}$ Int. Conf. New Ideas Agric., 52(2): 7.

Pakistan Meteorology Department, 2016. National data archives. Online at www.pmd.edu.pk

Qamar, H., M. Ilyas, S.A. Jan, H. Mustafa, A. Arshad and S. Yar. 2020. Recent trends in molecular breeding and biotechnology for the genetic improvement of brassica species against drought stress. Fresen. Environ. Bull., 29: 19-25.

Qi, Yiping (Ed.). 2019. Plant Genome Editing with CRISPR Systems Methods and Protocols. Springer book publishers, ISBN 978-1-49398991-1

Rahman, M.H., A. Ahmad, X. Wang, A. Wajid, W. Nasim, M.Hussain, B. Ahmad,I.Ahmad,Z.Ali, W. Ishaque, M. Awais, V. Shelia, S. Ahmad, S. Fahd, M. Alam, H. Ullah and G. Hoogenboom. 2018. Multi-model projections of future climate and climate change impacts uncertainty assessment for cotton production in Pakistan. Agric. For. Meteorol., 253-254: 94-113. https:// doi.org/10.1016/j.agrformet.2018.02.008 
Raza, A., A. Razzaq, S.S. Mehmood, X. Zou, X. Zhang, Y. Lv and J. Xu. 2019. Impact of climate change on crops adaptation and strategies to tackle its outcome: A review. Plants, 8(2): 34. https://doi.org/10.3390/plants8020034

Reddy, S. and R.R. Sharma. 2016. Effect of preharvest application of salicylic acid on the postharvest fruit quality of the Amrapali mango (Mangifera indica). Indian J. Agric. Sci., 73(3): 405-409. https://doi.org/10.5958/09740112.2016.00086.4

Rivas-San V.M. and J. Plasencia. 2011. Salicylic acid beyond defence: Its role in plant growth and development. J. Exp. Bot., 62(10): 33213338. https://doi.org/10.1093/jxb/err031

Shirzadeh, E. and M. Kazemi. 2012. Effect of salicylic acid and essential oils treatments on quality characteristics of apple (Malus domestica Var. Granny Smith) fruits during storage. Asian J. Biochem., 7(3): 165-170. https://doi. org/10.3923/ajb.2012.165.170

Tao, F. and Z. Zhang. 2013. Climate change, wheat productivity and water use in the North China Plain: A new super-ensemble-based probabilistic projection. Agric. For. Meteorol., 170: 146-165. https://doi.org/10.1016/j. agrformet.2011.10.003

USDA, 2016. Livestock and poultry: World markets and trade. U. S. Dept. Agric. Foreign Agric. Service.

Wani, A.B., H. Chadar, A.H. Wani, S. Singh and N. Upadhyay. 2017. Salicylic acid to decrease plant stress. Environ. Chem. Lett., 15: 101-123. https://doi.org/10.1007/s10311-016-0584-0

Zhou, X., L. Tang, Y. Xu, G. Zhou and Z. Wang. 2014. Towards a better understanding of medicinal uses of Carthamus tinctorius L. in traditional Chinese medicine. Phytochem. Pharmacol. Rev., 151(1): 27-43. https://doi. org/10.1016/j.jep.2013.10.050 